Tohoku J. Exp. Med., 2009, 218, 141-147

\title{
Lycopene, an Antioxidant Carotenoid, Attenuates Testicular Injury Caused by Ischemia/Reperfusion in Rats
}

\author{
Askin Hekimoglu, ${ }^{1}$ Zehra Kurcer, ${ }^{2}$ Faruk Aral, ${ }^{3}$ Füsun Baba, ${ }^{4}$ Engin Sahna ${ }^{5}$ and \\ Ahmet Atessahin ${ }^{6}$ \\ ${ }^{1}$ Department of Pharmacology, Faculty of Medicine, Dicle University, Diyarbakir, Turkey \\ ${ }^{2}$ Department of Pharmacology, Faculty of Medicine, Karaelmas University, Zonguldak, Turkey \\ ${ }^{3}$ Department of Artificial Insemination and Reproduction, Faculty of Veterinary Medicine, Harran University, \\ Sanliurfa, Turkey \\ ${ }^{4}$ Department of Pathology, Faculty of Medicine, Selcuk University, Konya, Turkey \\ ${ }^{5}$ Department of Pharmacology, Faculty of Medicine, Frrat University, Elazig, Turkey \\ ${ }^{6}$ Department of Pharmacology and Toxicology, Faculty of Veterinary Medicine, Firat University, Elazig, Turkey
}

\begin{abstract}
Testicular torsion is a common syndrome that could lead to infertility. We investigated the therapeutic effects of lycopene, an antioxidant caretenoid, on testicular ischemia/reperfusion (IR) injury that resembles testicular torsion. Male Wistar albino rats were divided into three groups: sham $(n=6)$, IR $(n=18)$, and ischemia/reperfusion with lycopene (IRL, $n=18$ ). Left testicular artery and vein was occluded for $1 \mathrm{~h}$, followed by reperfusion of $3 \mathrm{~h}, 24 \mathrm{~h}$ or 30 days in IR and IRL animals. Either corn oil (vehicle) or lycopene ( $4 \mathrm{mg} / \mathrm{kg}$ ) was administrated once daily by gavage to IR or IRL animals, respectively, $5 \mathrm{~min}$ after ischemia. Sham-operated animals were treated with vehicle by gavage $5 \mathrm{~min}$ after the operation. IR decreased sperm motility and concentration in both ipsilateral and contralateral testes and increased abnormal sperm rate in ipsilateral testis after 30 days of reperfusion. Treatment with lycopene increased the motility in bilateral testes and decreased the rate of abnormal sperm in ipsilateral testis to the sham level, but did not increase sperm concentration in bilateral testes. IR increased the activities of catalase and glutathione peroxidase and the level of reduced glutathione by $24 \mathrm{~h}$ of reperfusion, but malondialdehyde remained unchanged. Lycopene treatment restored the enzyme activities but not the reduced glutathione level. Lycopene treatment also ameliorated the IR-induced tissue damage in bilateral testes. In conclusion, the therapeutic antioxidant effect of lycopene on germ cells could serve as a promising intervention to oxidative stressassociated infertility problems, such as testicular torsion. — Lycopene; Testis; Ischemia/Reperfusion; Catalase; Glutathione peroxidase.
\end{abstract}

Tohoku J. Exp. Med., 2009, 218 (2), 141-147. 두 2009 Tohoku University Medical Press

The current study is based on the possible therapeutic effect of lycopene, a carotenoid predominantly found in tomato on testicular ischemia/reperfusion (IR) injury. Occlusion of the artery and the vein of the testis and its subsequent release cause acute IR injury that resembles testicular torsion. Testicular torsion is a urological syndrome caused mainly by a twist in the spermatic cord has been implicated in testicular injury and infertility (Williamson 1977). Testicular torsion has a prevalence of approximately 1 case per 125 males (Srinivasan et al. 2007). This syndrome often leads to infertility of the ipsilateral (IL) (torted) and contralateral (CL) (not torted) testis, an outcome that makes surgical intervention mandatory (Filho et al. 2004). This phenomenon leads to decreased spermatogenesis and infertility (Turner et al. 1997). Testicular IR injury causes morphological and biochemical changes by both ischemia and reperfusion of the testicular tissue (Ozokutan et al. 2000). IR injuries are associated with overgeneration of reactive oxygen species (ROS) (Dokmeci et al. 2007). The major cause of testicular injury is ROS generated during reperfusion (Filho et al. 2004). ROS oxidize membrane lipids, proteins, and DNA, leading to cellular dysfunction and cell death (Globus et al. 1995).

Sperms are highly sensitivite to oxidative stress and particularly to lipid peroxidation (LPO) due to their high content of polyunsaturated fatty acids in the plasma membrane. The fatty acids are an essential requirement for the male germ cell to maintain sperm functions (Ollero et al. 1998; Henkel 2005). ROS can also indirectly produce oxidative stress by decreasing the enzymatic defenses of the

Received March 24, 2009; revision accepted for publication April 24, 2009.

Correspondence: Askin Hekimoglu, Assistant Professor, Department of Pharmacology, Faculty of Medicine, Dicle University, 21280,

Diyarbakir, Turkey.

e-mail: askinh@hotmail.com 
spermatozoa (Michael et al. 2009). Some of endogenous and exogenous factors may cause DNA damage, inhibition of protein synthesis and corruption of the sperm formation cycle, resulting in abnormal spermatogenesis and spermatozoa (Moustafa et al. 2004). The administration of antioxidants, such as resveratrol or ascorbate, to animals also improved testicular function (Orozco et al. 2003; Juan et al. 2005).

Lycopene, the acyclic form of $\beta$-carotene, is a red pigment and is one of the major carotenoids in Western diets. Lycopene intake comes predominantly from tomatoes and tomato products. Lycopene has unique chemical and structural properties (Clinton 1998). Lycopene is an antioxidant carotenoid without provitamin A activity and has been shown to be a more potent antioxidant than $\alpha$ - or $\beta$-carotene (Di Mascio et al. 1989) in human and animal studies (Agarwal and Rao 1998; Suganuma and Inakuma 1999; Atessahin et al. 2006a; 2006b; Turk et al. 2007). Thus, lycopene treatment may represent a new, non-hormonal option for therapeutic strategy in men suffering from ROSmediated infertility.

The aims of the study were to investigate the effects of IR on sperm characteristics, biochemical and histopathologic changes related to oxidative stress in the testicular tissue and to highlight the protective effect of lycopene on these parameters.

\section{Materials and Methods}

Animals

Forty two male Wistar albino rats (250-350 g) were obtained from University of Inonu, Faculty of Medicine, Experimental Research Center (Malatya, Turkey). The study was carried out in Experimental Research Unit of Firat University (Elazig, Turkey). All experiments in this study were performed in accordance with the "Principles of Laboratory Animal Care" (NIH publication No. 86-23, revised 1984) and were approved by the Committee on Animal Research at Firat University.

\section{Chemicals}

$\operatorname{Ketalar}^{\circledR}$ (Ketamine Hydrochloride) was purchased from Eczacibasi Inc, (İstanbul, Turkey) and Rompun ${ }^{\circledR}$ (Xylasine 2\%) from Bayer Turk Chemical Inc (İstanbul, Turkey). Lycopene 10\% FS (Redivivo TM, Code 7803) was obtained from DSM Nutritional Products (İstanbul, Turkey). The materials that used for biochemical measuraments were obtained from Sigma (St. Louis, MO, USA).

\section{Experimental groups and sample collection}

Male Wistar albino rats were randomly divided into three experimental groups: Sham $(n=6)$, ischemia/reperfusion (IR) group ( $n=$ $18)$, and ischemia/reperfusion with lycopene (IRL) groups $(n=18)$. The minimal number of the samples was selected according to the basis of the previous studies (Lysiak et al. 2003). Sham group received sham operation $+0.5 \mathrm{ml}$ vehicle (corn oil) by gavage $5 \mathrm{~min}$ after the operation. Epididymis and testes were collected after $24 \mathrm{~h}$ for the histopathologic analysis and evaluation of sperm characteristics. IR groups received 1 -h ischemia and $0.5 \mathrm{ml}$ vehicle $5 \mathrm{~min}$ after ischemia, then reperfused for $3 \mathrm{~h}, 24 \mathrm{~h}$ or 30 days, with maintaining vehicle treatment once a day through the end of the reperfusion period of 30 days. IRL groups received $1-\mathrm{h}$ ischemia and lycopene suspended in corn oil at the dose of $4 \mathrm{mg} / \mathrm{kg}$ (Elumalai et al. 2009) through gavage 5 min after ischemia, then reperfused for $3 \mathrm{~h}, 24 \mathrm{~h}$ and 30 days, with maintaining lycopene treatment once a day for 30 days. Evaluation of sperm characteristics was presented after 30 days of reperfusion. Biochemical measurements were performed in 3-h and 24-h reperfusion groups. Histopathologic examination was performed in $24-\mathrm{h}$ reperfusion groups.

\section{Surgery and experimental protocol}

All surgical procedures were performed under anesthesia by intraperitoneal (i.p.) injection of $75 \mathrm{mg} / \mathrm{kg}$ ketamine hydrochloride and $8 \mathrm{mg} / \mathrm{kg}$ xylazine. After an abdominal incision, the testicular artery and vein of the left testis were occluded with a vascular clamp for $1 \mathrm{~h}$; after this process, the clamp was removed and the organ was allowed to reperfusion for $3 \mathrm{~h}, 24 \mathrm{~h}$ and 30 days in different groups. Sham operations were performed in a similar fashion, except the vessels were not clamped (Kurcer et al. 2008).

The rats were sacrificed by cardiac blood collection following anesthetization at the end of the treatment period. Testes and epididymides were removed, cleared of adhering connective tissue. Sperm charecteristics were evaluated after 30 days of reperfusion. Testis samples isolated at 3-h and 24-h reperfusion groups were stored at $-80^{\circ} \mathrm{C}$ for the biochemical analysis. For histopathological examination, testis samples of 24 -h reperfusion groups were fixed in $10 \%$ formalin solution.

\section{Epididymal sperm concentration, motility and morphology}

For evaluation of sperm characteristics, the rats after 30-day reperfusion were used. The epididymis was minced finely by anatomical scissors in a Petri dish within $5 \mathrm{~mL}$ of physiological saline placed in a rocker for $10 \mathrm{~min}$ then sperms were allowed to be release from epididymal tissue for $2 \mathrm{~min}$ at room temperature. Epididymal sperms were counted using a modification of the method as described by Yokoi et al. (Yokoi et al. 2003) with a haemocytometer. Sperm suspension of $5 \mu 1$ was diluted with $95 \mu 1$ of phosphate-buffered saline (PBS, pH 7.4) solution containing $10 \%$ formalin and $10 \%$ sucrose. Approximately $10 \mu \mathrm{L}$ of the diluted sperm suspension was transferred to each counting chamber of the hemocytometer and was allowed to stand for $5 \mathrm{~min}$. The light microscope (Magnification, $200 \times$ ) was used to count settled cells. The motile sperm percentage was evaluated visually in each sample according to previously described methods (Sonmez et al. 2005), an aliquot of sperm suspension diluated with Tris-buffer solution (Tris (hydroxymethyl) aminomethane $3.63 \mathrm{~g}$, glucose $0.50 \mathrm{~g}$, citric acid $1.99 \mathrm{~g}$ and distilled water $100 \mathrm{ml}$ ) on a prewarmed $\left(37^{\circ} \mathrm{C}\right)$ slide under a prewarmed $\left(37^{\circ} \mathrm{C}\right)$ coverslip with light microscopy at $400 \times$ magnification. Motility estimation was performed from four different fields in each sample and the mean of the four estimations was used as the final motility score.

Sperm morphological examination was performed as follows. Smear was prepared on clean slides after staining the sperm with $1 \%$ eosin Y. The slides were air-dried and coded for subsequent examination. Sperm morphological evaluation was carried out using light microscope at $400 \times$ magnification (Shetty 2007).

\section{Biochemical measuraments}

The rats in 3-h and 24-h reperfusion groups were used for evaluation of biochemical parameters. The IL testis samples were used for 
the measurement of malondialdehyde (MDA), reduced glutathion (GSH), and catalase (CAT) and glutathione peroxidase (GSH-Px) activities. The protein concentration was measured by the method of Lowry et al. (1951). Protein levels were measured in homogenates for MDA and other parameters were analyzed in supernatant.

The weighed testicular tissues was homogenized with Teflonglass homogenizer in a buffer containing $1.15 \% \mathrm{KCl}$ to obtain $1: 10$ $(\mathrm{w} / \mathrm{v})$ whole homogenates. MDA was determined in whole homogenates. Homogenates were centrifuged at $18,000 \times \mathrm{g}\left(4^{\circ} \mathrm{C}\right)$ for $15 \mathrm{~min}$ to determine GSH concentrations, CAT activity and at 25,000 $\times \mathrm{g}$ for 50 min to determine GSH-Px activity (Yilmaz et al. 2006).

\section{Determination of malondialdehyde (MDA) levels}

The testicular tissue LPO was measured according to the concentration of thiobarbituric acid (TBA) reactive substances. The amount of produced MDA was used as an index of LPO (Ohkawa et al. 1979). In the TBA test reaction, MDA or MDA-like substances and TBA react with the production of a pink pigment with a maximum absorption at $532 \mathrm{~nm}$. The reaction was performed at $\mathrm{pH} 2-3$ at $90^{\circ} \mathrm{C}$ for $15 \mathrm{~min}$. The sample was mixed with 2 volumes of cold $10 \%$ $(\mathrm{w} / \mathrm{v})$ trichloroacetic acid for protein precipitation. The precipitate was pelleted by centrifugation, and an aliquot of the supernatant was reacted with an equal volume of $0.67 \%(w / v)$ TBA in a boiling water bath for $10 \mathrm{~min}$. After cooling, the absorbance was read at $532 \mathrm{~nm}$. The results were expressed as nmol/g wet tissue.

\section{Determination of catalase (CAT) activity}

The CAT activity in the testicular tissue was determined by measuring the decomposition of hydrogen peroxide at $240 \mathrm{~nm}$, according to the method of Aebi (Aebi 1984) and was expressed as $\mathrm{kU} / \mathrm{g}$ protein, where $\mathrm{k}$ is the first-order rate constant.

\section{Determination of Glutathione Peroxidase (GSH-Px) activity}

The GSH-Px activity in testicular tissue was determined according to the method of Lawrence and Burk (Lawrence and Burk 1976). The reaction mixture consisted of $50 \mathrm{mM}$ potassium phosphate buffer (pH 7.0), 1 mMEDTA, $1 \mathrm{mM}$ sodium azide (NaN3), $0.2 \mathrm{mM}$ reduced nicotinamide adenine dinucleotide phosphate (NADPH), $1 \mathrm{IU} / \mathrm{ml}$ oxidized glutathione (GSSG)-reductase, $1 \mathrm{mM} \mathrm{GSH}$, and $0.25 \mathrm{mM} \mathrm{H}_{2} \mathrm{O}_{2}$. Enzyme source $(0.1 \mathrm{ml})$ was added to $0.8 \mathrm{ml}$ of the above mixture and incubated at $25^{\circ} \mathrm{C}$ for $5 \mathrm{~min}$ before initiation of the reaction with the addition of $0.1 \mathrm{ml}$ of peroxide solution. The absorbance at $340 \mathrm{~nm}$ was recorded for $5 \mathrm{~min}$ on a spectrophotometer. The activity was calculated from the slope of the lines as micromoles of NADPH oxidized per min. The blank value (the enzyme was replaced with distilled water) was subtracted from each value. The GSH-Px activity was expressed as IU/g protein.

\section{Determination of reduced Glutathione (GSH) levels}

The reduced GSH level of testicular tissue was measured at 412 $\mathrm{nm}$ using the method of Sedlak and Lindsay (Sedlak and Lindsay 1968). Samples were precipitated with $50 \%$ trichloracetic acid, and then centrifuged at $1000 \times \mathrm{g}$ for $5 \mathrm{~min}$. The reaction mixture contained $0.5 \mathrm{ml}$ of supernatant, $2.0 \mathrm{ml}$ of Tris-EDTA buffer $(0.2 \mathrm{~mol} / \mathrm{l}$; $\mathrm{pH} 8.9$ ) and $0.1 \mathrm{ml}$ of $0.01 \mathrm{~mol} / \mathrm{L} \mathrm{5,5-dithiobis-2-nitrobenzoic} \mathrm{acid.}$ The solution was kept at room temperature for $5 \mathrm{~min}$, and then read at $412 \mathrm{~nm}$ on the spectrophotometer. The level of GSH was expressed as $\mathrm{nmol} / \mathrm{ml}$.

\section{Histolopathological Analysis}

The rats were sacrificed at $24 \mathrm{~h}$ of reperfusion for histopathologic evaluation. For light microscopic evaluation, testes were fixed in $10 \%$ neutral buffered formalin, processed routinely by automatic tissue processor and embedded in paraffin wax. Four $\mu \mathrm{m}$ sections were stained with hematoxylin-eosin (HE) before investigation under light microscopy (Olympus BX-51 TF, Tokyo, Japan). The seminiferous tubules were examined in ten consequtive high power fields with $400 \times$ magnification under light microscope and their histopathological biopsies were scored according to Johnsen's criteria (Johnsen 1970). The Johnsen score is based on the premise that with testicular damage there is successive disappearance of the most mature cell type, with progressive degeneration of germinal epithelium, and with the disappearance of sperm and spermatids, then spermatocytes and finally Sertoli cells, in that order. A score of 1 indicates no seminiferous epithelial cells and tubuler sclerosis; score 2, no germ cells, only Sertoli cells; score 3, spermatogonia only; score 4, no spermatids, since spermatocytes and arrest of spermatogenesis at the primary spermatocyte stage; score 5, no spermatids and many spermatocytes; score 6, no late spermatids with few early spermatids, arrest of spermatogenesis at the spermatid stage, and disturbance of spermatid differentiation; score 7, no late spermatids and many early spermatids; score 8, few late spermatids; score 9, late spermatids and disorganised tubuler epithelium; and score 10, full spermatogenesis.

\section{Statistical Analysis}

All data were expressed as the arithmetic mean \pm SEM. $P<0.05$ was considered to be statistically significant. The sperm concentration and motility data were analyzed by oneway analyse of variance (ANOVA) and post doc Tukey-HSD. Paired student t-test and Wilcoxon test were used to assess the differences between IL and CL testes. Biochemical results were statistically analyzed by ANOVA. The histopathological results and abnormal sperm rate were statistically analyzed by the Kruskal-Wallis $\mathrm{H}$ test. The differences between the groups were evaluated by the Mann-Whitney U test. In the tables, the $p$ values of ANOVA tests for the parametric data and $p$ values of Kruskal-Wallis $\mathrm{H}$ tests for non-parametric data were provided. In the results section $\mathrm{p}$ values of post doc tests were provided. Statistical analyse were carried out by using the statistical packages for SPSS 11.0 for Windows (SPSS Inc., Chicago, IL, USA).

\section{Results}

Sperm Analysis

The results of the sperm characteristics are shown in Table 1. IR caused significant differences in the tissue damages between CL and IL testes for the sperm motility ( $p=$ $0.006)$, sperm concentration $(p=0.001)$ and abnormal sperm rate $(p=0.006)$. IR decreased sperm motility in bilateral testes, while lycopene treatment prevented the decrease in motility in bilateral testes and reversed it to the sham level in CL testis $(p=0.019)$. Lycopene treatment differentially affected sperm motility between IL and CL testes $(p=0.015)$. Sperm concentration was decreased by IR in bilateral testes, which was, hoewever, not restored by lycopene treatment $(p=0.001)$. Abnormal sperm rate was increased significantly only in IL testis, and lycopene treatment decreased the abnormal sperm rate in IL testis to the level of sham animals $(p=0.014)$. 
Table 1. Epididymal sperm analysis of the IL and CL testes after 30 days of reperfusion.

\begin{tabular}{|c|c|c|c|c|c|c|}
\hline \multirow[b]{2}{*}{ Groups } & \multicolumn{2}{|c|}{$\begin{array}{l}\text { MOTILITY } \\
(\%)\end{array}$} & \multicolumn{2}{|c|}{$\begin{array}{l}\text { SPERM CONCENTRATION } \\
\left(\times 10^{-6}\right)\end{array}$} & \multicolumn{2}{|c|}{$\begin{array}{l}\text { ABNORMAL SPERM RATE } \\
(\%)\end{array}$} \\
\hline & IL & $\mathrm{CL}$ & $\mathrm{IL}$ & CL & IL & $\mathrm{CL}$ \\
\hline Sham & $66.0 \pm 1.15^{\mathrm{b}}$ & $65.2 \pm 1.19^{\mathrm{b}}$ & $220.0 \pm 56.98^{\mathrm{b}}$ & $261.7 \pm 37.71^{\mathrm{b}}$ & $6.7 \pm 1.41^{\mathrm{b}}$ & $5.3 \pm 1.45$ \\
\hline IR & $23.9 \pm 4.23^{\mathrm{a} * *}$ & $41.0 \pm 6.72^{\mathrm{a}}$ & $42.2 \pm 22.99^{\mathrm{a} * *}$ & $149.1 \pm 20.84^{\mathrm{a}}$ & $21.9 \pm 3.48^{\mathrm{a} * *}$ & $7.2 \pm 2.18$ \\
\hline IRL & $45.7 \pm 7.20^{\mathrm{ab} *}$ & $63.5 \pm 8.16^{\mathrm{b}}$ & $52.3 \pm 19.53^{\mathrm{a}}$ & $91.16 \pm 11.46^{\mathrm{a}}$ & $17.3 \pm 6.29^{b}$ & $7.1 \pm 1.90$ \\
\hline$p$ & 0.0001 & 0.019 & 0.0001 & 0.0001 & 0.014 & \\
\hline
\end{tabular}

The sham-operated animals (sham) were analyzed at 30 days after operation. Data shown as mean values \pm SEM. ${ }^{\text {a }}$ different from sham $(p<0.05),{ }^{\text {b: }}$ different from IR $(p<0.05)$, ab: different from sham and IR $(p<0.05)$. * and **: Ipsilateral testis (IL) that are significantly different from the contralateral testis (CL) $(*: p<0.05 ; * *<0.01)$ are marked with an asterisk $(*)$.

IR, Ischemia/reperfusion; IRL, Ischemia/reperfusion + Lycopene.

Table 2. Biochemical analyse of ipsilateral testes at $3 \mathrm{~h}$ and $24 \mathrm{~h}$ after reperfusion.

\begin{tabular}{|c|c|c|c|c|c|c|c|c|}
\hline \multirow[b]{2}{*}{ Groups } & \multicolumn{2}{|c|}{$\begin{array}{c}\text { MDA } \\
\mathrm{nmol} / \mathrm{g} \text { wet tissue }\end{array}$} & \multicolumn{2}{|c|}{$\begin{array}{c}\text { CAT } \\
\mathrm{kU} / \mathrm{g} \text { protein }\end{array}$} & \multicolumn{2}{|c|}{$\begin{array}{l}\text { GSH-Px } \\
\text { IU/g protein }\end{array}$} & \multicolumn{2}{|c|}{$\underset{\mathrm{nmol} / \mathrm{ml}}{\mathrm{GSH}}$} \\
\hline & $3 \mathrm{~h}$ & $24 \mathrm{~h}$ & $3 \mathrm{~h}$ & $24 \mathrm{~h}$ & $3 \mathrm{~h}$ & $24 \mathrm{~h}$ & $3 \mathrm{~h}$ & $24 \mathrm{~h}$ \\
\hline Sham & - & $24.01 \pm 3.12$ & - & $3.9 \pm 0.49^{\mathrm{b}}$ & - & $60.7 \pm 4.13^{\mathrm{b}}$ & - & $2.4 \pm 0.26^{\mathrm{b}}$ \\
\hline IR & $19.2 \pm 3.10$ & $22.2 \pm 4.64$ & $3.9 \pm 0.92$ & $6.6 \pm 1.10^{\mathrm{a}}$ & $61.9 \pm 4.34$ & $87.1 \pm 11.85^{\mathrm{a} *}$ & $2.8 \pm 0.32$ & $4.9 \pm 0.65^{\mathrm{a} *}$ \\
\hline IRL & $16.3 \pm 2.66$ & $19.3 \pm 2.89$ & $2.6 \pm 0.44$ & $2.8 \pm 0.5^{\mathrm{b}}$ & $50.9 \pm 2.94^{\mathrm{ab}}$ & $62.4 \pm 3.58^{\mathrm{b} *}$ & $3.1 \pm 0.23$ & $5.5 \pm 0.66^{\mathrm{a} *}$ \\
\hline$p$ & \multicolumn{2}{|c|}{0.508} & \multicolumn{2}{|c|}{0.052} & \multicolumn{2}{|c|}{0.0001} & \multicolumn{2}{|c|}{0.0001} \\
\hline
\end{tabular}

The sham-operated animals were analyzed only at $24 \mathrm{~h}$ after operation. Data shown as mean values \pm SEM. ${ }^{\text {a }}$ different from sham $(p<0.05),{ }^{\text {b}}$ : different from IR $(p<0.05)$, ab: different from sham and IR $(p<0.05)$. $*: 24$ h groups that are statistically different from $3 \mathrm{~h}$ groups for IR and IRL groups $(p<0.05)$

IR, Ischemia/reperfusion; IRL, Ischemia/reperfusion + Lycopene; MDA, Malondialdehyde; CAT, Catalase; GSH-Px, Glutathione Peroxidase; GSH, Glutathione.

\section{Biochemical results}

We measured the levels of MDA and GSH and the activities of CAT and GSH-Px in IL testis (Table 2). MDA levels were similar in all groups. CAT levels were also not affected by IR $(p=0.730)$ or lycopene treatments $(p=$ $0.358)$ at 3-h reperfusion. IR significantly increased CAT levels $(p=0.048)$ and lycopene treatment reversed the increased CAT levels to the sham level at $24 \mathrm{~h}(p=0.478)$. CAT levels were increased at $24 \mathrm{~h}$, which was significantly higher compared to the level at $3 \mathrm{~h}(p=0.006)$. There were significant differences in GSH-Px levels in IR groups between $3 \mathrm{~h}$ and $24 \mathrm{~h}(p=0.0001)$. GSH-Px levels were incerased at $24 \mathrm{~h}$ of IR ( $p=0.0001)$ and lycopene administration reversed the increased GSH-Px levels to the sham level $(p=0.875)$. GSH-Px levels were not increased at $3 \mathrm{~h}$ of IR, but lycopene treatment decreased GSH-Px levels even lower than the sham level $(p=0.020)$. GSH levels were not affected by $3 \mathrm{~h}$ of IR, but at $24 \mathrm{~h}$ of IR, GSH levels were significantly increased $(p=0.0001)$. Accordingly, GSH levels at $24 \mathrm{~h}$ of IR or LIR were significantly higher than those at $3 \mathrm{~h}$ of IR or IRL $(p=0.001)$. Lycopene administration did not affect the GSH levels $(p=0.0001)$.

\section{Histopathological Results}

The testicular biopsy scores that reflect the degree of
Table 3. Semiquantitative estimates of testicular injury at $24 \mathrm{~h}$ after reperfusion.

\begin{tabular}{lcc}
\hline Groups & IL testis score & CL testis score \\
\hline Sham & $8.9 \pm 0.18^{\mathrm{b}}$ & $8.7 \pm 0.18^{\mathrm{b}}$ \\
IR & $6.2 \pm 0.11^{\mathrm{a}}$ & $6.2 \pm 0.12^{\mathrm{a}}$ \\
IRL & $8.6 \pm 0.22^{\mathrm{ab}}$ & $8.4 \pm 0.08^{\mathrm{b}}$ \\
$p$ & 0.0001 & 0.001 \\
\hline
\end{tabular}

The sham-operated animals were analyzed at $24 \mathrm{~h}$ after operation. Data shown as mean values \pm SEM. a: different from sham $(p<0.05),{ }^{\text {b: }}$ different from IR $(p<$

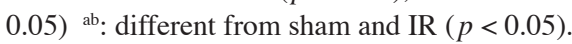

IL, Ipsilateral testis; CL, contralateral testis; IR, Ischemia/reperfusion; IRL, Lycopene + ischemia/ reperfusion.

tissue injury are shown in Table 3. IR decreased testicular biopsy scores in both IL (Fig. 1A) and CL testes ( $p=0.003$, $p=0.003$ ). Complete maturation arrest, disorganisation and slouging of immature germ cells into tubule lumen and apoptotic changes were observed. Lycophene treatment prevented IR injury in both IL ( $p=0.015)$ and CL testes (Fig. 1B) and reversed to the sham level in CL testis $(p=0.666)$ (Fig. 1C). There were no significant differences between IL and CL scores in any group $(p=0.377)$. 

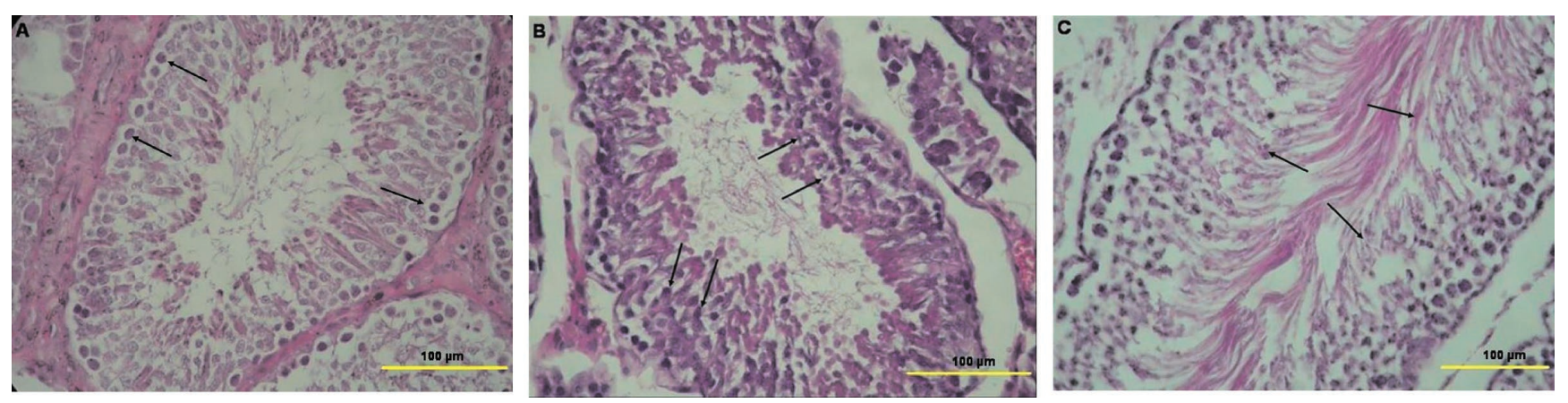

Fig. 1. Histopathology of the ipsilateral testicular tissue after ischemia/reperfusion.

A: The representative tissue section of IR rats. Complete maturation arrest with immature spermatogonia lying along the tubule basement membrane (arrows). HE, $400 \times$. (IR: Ischemia reperfusion)

B: The representative tissue section of IRL rats. Start of maturation; germ cells' nuclei and cytoplasms become smaller towards the lumen (arrows) however there are very few mature spermatids without tails (arrows). HE, $400 \times$. (IRL: Ischemia Repefusion + Lycopene)

$\mathrm{C}$ : The representative tissue section of sham-operated rats. Orderly spermatogenetic maturation and mature sparmatids in the lumen (arrows). HE, $400 \times$.

\section{Discussion}

Prolonged testicular torsion leads to testicular ischaemia and high levels of oxidative stress with ROS production (Taneli et al. 2005). ROS-induced oxidative stress was increased in testicular tissue following detorsion, indicates the reperfusion injury (Guimaraes et al. 2007). ROS are highly reactive oxidizing agents belonging to the class of free-radicals, which contain one or more unpaired electrons (Sikka 1996). Oxidative stress induces poor sperm function while mammalian spermatozoa membranes are very sensitive to the damage mediated by LPO, as they are rich in polyunsaturated fatty acids. Besides, Leydig cell mitochondria and microsomes of testes are known to contribute significantly to an increased generation of ROS (Mishra and Acharya 2004). Many clinical and experimental trials of antioxidant agents have been attempted to protect spermatogenesis from ROS-induced testicular damage. Lycopene is known to be an efficient scavenger of singlet oxygen ( $\left.{ }^{1} \mathrm{O} 2\right)$ (Di Mascio et al. 1989). During ${ }^{1} \mathrm{O} 2$ quenching, energy is transfered from ${ }^{1} \mathrm{O} 2$ to the lycopene molecule, converting it to the energy-rich triplet state. Trapping of ROS, such as peroxynitrite, leads to oxidative breakdown of the lycopene molecule. Thus, lycopene may protect in vivo against oxidation of lipids, proteins and DNA (Gupta and Kumar 2002; Stahl and Sies 2003; Wertz et al. 2004).

It has been suggested that IR injury may adversely affect the quality and quantity of sperm, which is responsible for male fertility (Steinberger and Tjioe 1969). Increased oxidative stress damages the sperm membranes, proteins, and DNA (Sikka 1996; Sanocka and Kurpisz 2004). Both sperm concentration and motility were reduced on 30 days after 1-h torsion in rats (Payabvash et al. 2008). Similarly, our data suggest that the 1-h ischemia causes a decrease in sperm concentration and motility in bilateral testes and abnormal sperm rate in IL testis 30 days after ischemia. In this study lycopene administration increased the IR-induced decrease in sperm motility in bilateral testes and reversed it to the sham level in CL testis. Epididymal sperm concentration was decreased by IR; however, lycopene administration failed to increase the decreased sperm concentration in bilateral testes. Lycopen treatment decreased the IR-induced abnormal sperm rate in IL testis. The detrimental effects of IR on the sperm concentration suggest an interference with spermatogenesis; ischemia may induce necrotic degeneration of testicular tissues, which may contribute to loss of spermatogenesis in testis. The IRinduced oxidative stress may be responsible for the decrease in sperm concentration in testicular tissue. Oxidative stress is known to show detrimental effects on the testis function via the induction of peroxidative damage to the plasma membrane (Visser and Heyns 2003). The loss of sperm function was shown to be due to the peroxidation of unsaturated fatty acids in plasma membrane of sperm (Kato et al. 2001).

It was reported that regular lycopene intake for 9 months in oligoasthenospermia patients improved the sperm concentration, sperm motility and sperm morphology (Mohanty et al. 2001). Also oral lycopene therapy in men with idiopathic infertility provided an improvement in male infertility, especially in sperm characteristics (Gupta and Kumar 2002). In addition, it has been reported that lycopene has protective roles on spermatogenesis on various oxidative damage related testicular toxicity animal models (Atessahin et al. 2006a; 2006b; Turk et al. 2007). Similarly as shown in this study, the protective effects of lycopene against IR-induced loss of sperm function may be attributed to the antioxidant properties of lycopene.

Testicular tissue and seminal plasma are endowed with antioxidant enzymes and free radical scavengers to protect spermatogenic functions from oxidative stress. These antioxidant defense systems are of major importance as peroxidative damage is currently regarded as the most important cause of impaired testicular functions (Khosrowbeygi and 
Zarghami 2007; Aitken and Roman 2007). Besides ROS must be inactivated continuosly to keep only a small amount necessary to maintain normal cell function (Alvarez and Storey 1995). Despite these antioxidant defense systems, this tissue remains vulnerable to oxidative stress due to the abundance of highly unsaturated fatty acids and the presence of potential ROS-generating systems (Khosrowbeygi and Zarghami 2007; Aitken and Roman 2007).

In the present study, MDA levels were not noticeably changed by IR or lycopene administration. In this connection, Bonnes-Taourel et al. (1992) suggest that measurements of MDA production in living systems, in the presence of ROS, could be underestimated. On the other hand, in the present study, the significant increase was observed in CAT, GSH and GSH-Px activities $24 \mathrm{~h}$ after IR, which may be due to the IR-induced LPO. Lycopene administration reversed the IR-induced elevation in CAT and GSH-Px activities to the sham level, without affecting GSH levels at $24 \mathrm{~h}$ reperfusion. The administration of antioxidants such as resveratrol, ascorbate or cocoa rich in flavanols to animals, not suffering from induced oxidative stress, also improved testicular function, suggesting that oxidative stress is a consistent feature of testicular physiology (Orozco et al. 2003; Juan et al. 2005). The protective effect of lycopene against the IR-induced increase in ROS generation may be due to its ability to react with the oxygen metabolites.

In summary, IR decreased sperm concentration and motility and increased abnormal sperm rate. Significant normalization of these parameters was observed with lycopene treatment. The protective effects of lycopene against IR-induced abnormal sperm rates and decreased motility may be attributable to the antioxidant properties of lycopene. These observations also indicate that lycopene has therapeutic effects on the IR-induced oxidative injury in the testis. The present study suggests that the therapeutic effect of lycopene on germ cells could serve as a promising intervention to oxidative stress-associated infertility problems, such as testicular torsion.

\section{References}

Aebi, H. (1984) Catalase in vitro. Methods Enzymol., 105, 121-126.

Agarwal, S. \& Rao, A.V. (1998) Tomato lycopene and low density lipoprotein oxidation: a human dietary intervention study. Lipids, 33, 981-984.

Aitken, R.J. \& Roman, S.D. (2007) Antioxidant systems and Oxidative Stress in Testis. In Molecular Mechanisms in Spermatogenesis. Edited by Cheng C.Y., Antioxidant Series: Advances in Experimental Medicine and Biology. Landes Bioscience and Springer Verlag, 636, 154-171.

Alvarez, J.G. \& Storey, B.T. (1995) Differential incorporation of fatty acids into and peroxidative loss of fatty acids from phospholipids of human spermatozoa. Mol. Reprod. Dev., 42, 334-346.

Atessahin, A., Turk, G., Karahan, I., Yilmaz, S., Ceribasi, A.O. \& Bulmus, O. (2006a) Lycopene prevents adriamycin-induced testicular toxicity in rats. Fertil. Steril., 85, 1216-1222.

Atessahin, A., Karahan, I., Turk, G., Gur, S., Yilmaz, S. \& Ceribasi,
A.O. (2006b) Protective role of lycopene on cisplatin-induced changes in sperm characteristics, testicular damage and oxidative stress in rats. Reprod. Toxicol., 21, 42-47.

Bonnes-Taourel, D., Guerin, M.C. \& Torreilles, J. (1992) Is malonaldehyde a valuable indicator of lipid peroxidation? Biochem. Pharmacol., 44, 985-988.

Clinton, S.K. (1998) Lycopene: chemistry, biology, and implications for human health and disease. Nutr. Rev., 56, 35-51.

Di Mascio, P., Kaiser, S. \& Sies, H. (1989) Lycopene as the most efficient biological carotenoid singlet oxygen quencher. Arch. Biochem. Biophys., 274, 532-538.

Dokmeci, D., Kanter, M., Inan, M., Aydogdu, N., Basaran, U.N., Yalcin, O. \& Turan, F.N. (2007) Protective effects of ibuprofen on testicular torsion/detorsion-induced ischemia/ reperfusion injury in rats. Arch. Toxicol., 81, 655-663.

Elumalai, P., Krishnamoorthy, G., Selvakumar, K., Arunkumar, R., Venkataraman, P. \& Arunakaran, J. (2009) Studies on the protective role of lycopene against polychlorinated biphenyls (Aroclor 1254)-induced changes in StAR protein and cytochrome P450 scc enzyme expression on Leydig cells of adult rats. Reprod. Toxicol., 27, 41-45.

Filho, D.W., Torres, M.A., Bordin, A.L., Crezcynski-Pasa, T.B. \& Boveris, A. (2004) Spermatic cord torsion, reactive oxygen and nitrogen species and ischemia-reperfusion injury. Mol. Aspects Med., 25, 199-210.

Globus, M.Y., Busto, R., Lin, B., Schnippering, H. \& Ginsberg, M.D. (1995) Detection of free radical activity during transient global ischemia and recirculation: effects of intraischemic brain temperature modulation. J. Neurochem., 65, 1250-1256.

Guimaraes, S.B., Aragao, A.A., Santos, J.M., Kimura, Ode. S., Barbosa, P.H. \& Vasconcelos, P.R. (2007) Oxidative stress induced by torsion of the spermatic cord in young rats. Acta Cir. Bras., 22, 30-33.

Gupta, N.P. \& Kumar, R. (2002) Lycopene therapy in idiopathic male infertility - a preliminary report. Int. Urol. Nephrol., 34, 369-372.

Henkel, R. (2005) The impact of oxidants on sperm function. Andrologia, 37, 205-206.

Johnsen, S.G. (1970) Testicular biopsy score count-a method for registration of spermatogenesis in human testes: normal values and results in 335 hypogonadal males. Hormones, 1, 2-25.

Juan, M.E., González-Pons, E., Munuera, T., Ballester, J., Rodríguez-Gil, J.E. \& Planas, J.M. (2005) trans-Resveratrol, a natural antioxidant from grapes, increases sperm output in healthy rats. J. Nutr., 135, 757-760.

Kato, M., Makino, S., Kimura, H., Ota, T., Furuhashi, T. \& Nagamura, Y. (2001) Sperm motion analysis in rats treated with adriamycin and its applicability to male reproductive toxicity studies. J. Toxicol. Sci., 26, 51-59.

Khosrowbeygi, A. \& Zarghami, N. (2007) Levels of oxidative stress biomarkers in seminal plasma and their relationship with seminal parameters. BMC Clin. Pathol., 7, 6.

Kurcer, Z., Oguz, E., Ozbilge, H., Baba, F., Aksoy, N. \& Celik, N. (2008) Effect of melatonin on testicular ischemia/reperfusion injury in rats: is this effect related to the proinflammatory cytokines? Fertil. Steril., 89(5), 1468-1473.

Lawrence, R.A. \& Burk, R.F. (1976) Glutathione peroxidase activity in selenium-deficient rat liver. Biochem. Biophys. Res. Commun., 71, 952-958.

Lowry, O.H., Rosebrough, N.J., Farr, A.L. \& Randall, R.J. (1951) Protein measurement with Folin phenol reagent. J. Biol. Chem., 193, 265-275.

Lysiak, J.J., Nguyen, Q.A., Kirby, J.L. \& Turner, T.T. (2003) Ischemia-reperfusion of the murine testis stimulates the expression of proinflammatory cytokines and activation of c-jun N-terminal kinase in a pathway to E-selectin expression. Biol. Reprod., 69, 202-210.

Michael, J.A., Alexopoulos, C., Pontiki, E.A., Hadjipavlou-Litina, D.J., Saratsis, P., Ververidis, H.N. \& Boscos, C.M. (2009) 
Effect of antioxidant supplementation in semen extenders on semen quality and reactive oxygen species of chilled canine spermatozoa. Anim. Reprod. Sci., 112, 119-135.

Mishra, M. \& Acharya, U.R. (2004) Protective action of vitamins on the spermatogenesis in lead-treated Swiss mice. J. Trace Elem. Med. Biol., 18, 173-178.

Mohanty, N.K., Kumar, S., Jha, A.K. \& Arora, R.P. (2001) Management of idiopathic oligoasthenospermia with lycopene. Indian J. Urol., 18, 57-61.

Moustafa, M.H., Sharma, R.K., Thornton, J., Mascha, E., Abdel-Hafez, M.A., Thomas, A.J. Jr. \& Agarwal, A. (2004) Relationship between ROS production, apoptosis and DNA denaturation in spermatozoa from patients examined for infertility. Hum. Reprod., 19, 129-138.

Ohkawa, H., Ohishi, N. \& Yagi, K. (1979) Assay for lipid peroxides in animal tissues by thiobarbituric acid reaction. Anal. Biochem., 95, 351-358.

Ollero, M., Perez-Pe, R., Muino-Blanco, T. \& Cebrian-Perez, J.A. (1998) Improvement of ram sperm cryopreservation protocols assessed by sperm quality parameters and heterogeneity analysis. Cryobiol., 37, 1-12.

Orozco, T.J., Wang, J.F. \& Keen, C.L. (2003) Chronic consumption of a flavanol- and procyanindin-rich diet is associated with reduced levels of 8-hydroxy-2'-deoxyguanosine in rat testes. $J$. Nutr. Biochem., 14, 104-110.

Ozokutan, B.H., Küçükaydin, M., Muhtaroğlu, S. \& Tekin, Y. (2000) The role of nitric oxide in testicular ischemia-reperfusion injury. J. Pediatr. Surg., 35, 101-103.

Payabvash, S., Kiumehr, S., Tavangar, S.M. \& Dehpour, A.R. (2008) Ethyl pyruvate reduces germ cell-specific apoptosis and oxidative stress in rat model of testicular torsion/detorsion. $J$. Pediatr. Surg., 43, 705-712.

Sanocka, D. \& Kurpisz, M. (2004) Reactive oxygen species and sperm cells. Reprod. Biol. Endocrinol., 2, 12.

Sedlak, J. \& Lindsay, R.H. (1968) Estimation of total, proteinbound and nonprotein sulfhydryl groups in tissue with Ellman's reagent. Anal. Biochem., 25, 192-205.

Shetty, A.J. (2007) The effect of gabapentin and phenytoin on sperm morphology in Wistar rats. Reprod. Biol., 7, 247-251.
Sikka, S.C. (1996) Oxidative stress and role of antioxidants in normal and abnormal sperm function. Front. Biosci., 1, 78-86.

Sonmez, M., Turk, G. \& Yuce, A. (2005) The effect of ascorbic acid supplementation on sperm quality, lipid peroxidation and testosterone levels of male Wistar rats. Theriogenology, $\mathbf{6 3}$, 2063-2072.

Srinivasan, A.K., Freyle, J., Gitlin, J.S. \& Palmer, L.S. (2007) Climatic conditions and the risk of testicular torsion in adolescent males. J. Urol., 178, 2585-2588.

Stahl, W. \& Sies, H. (2003) Antioxidant activity of carotenoids. Mol. Aspects Med., 24, 345-351.

Steinberger, E. \& Tjioe, D.Y. (1969) Spermatogenesis in rat testes after experimental ischemia. Fertil. Steril., 20, 639-649.

Suganuma, H. \& Inakuma, T. (1999) Protective effect of dietary tomato against endothelial dysfunction in hypercholesterolemic mice. Biosci. Biotechnol. Biochem., 63, 78-82.

Taneli, F., Vatansever, S., Ulman, C., Yilmaz, O., Giray, G., Genç, A. \& Taneli, C. (2005) The effect of spermatic vessel ligation on testicular nitric oxide levels and germ cell-specific apoptosis in rat testis. Acta Histochem., 106, 459-466.

Turner, T.T., Tung, K.S., Tomomasa, H. \& Wilson, L.W. (1997) Acute testicular ischemia results in germ cell-specific apoptosis in the rat. Biol. Reprod., 57, 1267-1274.

Turk, G., Atessahin, A., Sonmez, M., Yuce, A. \& Ceribasi, A.O. (2007) Lycopene protects against cyclosporine A-induced testicular toxicity in rats. Theriogenoly, 67, 778-785.

Visser, A.J. \& Heyns, C.F. (2003) Testicular function after torsion of the spermatic cord. BJU Int., 92, 200-203.

Wertz, K., Siler, U. \& Goralczyk, R. (2004) Lycopene: modes of action to promote prostate health. Arch. Biochem. Biophys., 430, 127-134.

Williamson, R.C. (1977) Death in the scrotum: testicular torsion. N. Engl. J. Med., 296, 338.

Yilmaz, S., Atessahin, A., Sahna, E., Karahan, I. \& Ozer, S. (2006) Protective effect of lycopene on adriamycin-induced cardiotoxicity and nephrotoxicity. Toxicology, 218, 164-171.

Yokoi, K., Uthus, E.O. \& Nielsen, F.H. (2003) Nickel deficiency diminishes sperm quantity and movement in rats. Biol. Trace Elem. Res., 93, 141-154. 